\title{
Metformin Use Associated with Reduced Risk of Dementia in Patients with Diabetes: A Systematic Review and Meta-Analysis
}

\author{
Jared M. Campbell ${ }^{\mathrm{a}, \mathrm{b}, *}$, Matthew D. Stephenson ${ }^{\mathrm{a}}$, Barbora de Courten $^{\mathrm{c}}$, Ian Chapman ${ }^{\mathrm{d}}$, \\ Susan M. Bellman ${ }^{\mathrm{a}}$ and Edoardo Aromataris ${ }^{\mathrm{a}}$ \\ ${ }^{a}$ Joanna Briggs Institute, Faculty of Health and Medical Sciences, The University of Adelaide, South Australia \\ ${ }^{\mathrm{b}}$ Centre for Nanoscale BioPhotonics, Faculty of Science and Engineering, Macquarie University, \\ Sydney, New South Wales \\ ${ }^{\mathrm{c}}$ Monash Centre for Health, Research and Implementation, School of Public Health and Preventive Medicine, \\ Monash University, Melbourne, Australia \\ ${ }^{\mathrm{d}}$ Discipline of Medicine, National Health and Medical Research Council of Australia (NHMRC) \\ Centre of Research Excellence in Translating Nutritional Science to Good Health, \\ University of Adelaide, Adelaide, Australia
}

Accepted 23 July 2018

\begin{abstract}
.
Background: Metformin, a first line antihyperglycemic medication, is an AMPK activator and has been hypothesized to act as a geroprotective agent. Studies on its association with various classifications of age-related cognitive decline have shown mixed results with positive and negative findings.

Objective: To synthesize the best available evidence on the association of metformin-use with risk, progression, and severity of dementia.

Method: Eligible research investigated the effect of metformin on dementia, Alzheimer's disease, or any measure of cognitive impairment compared to any control group who were not receiving metformin. The initial search resulted in 862 citations from which 14 studies (seven cohort, four cross-sectional, two RCTs, and one case control) were included.

Results: Meta-analysis of three studies showed that cognitive impairment was significantly less prevalent in diabetic metformin (Odds ratio $=0.55,95 \%$ CI 0.38 to 0.78 ), while six studies showed that dementia incidence was also significantly reduced (Hazard ratio $=0.76,95 \%$ CI 0.39 to 0.88 ). Mini-Mental State Examination scores were not significantly affected by metformin-use, although both RCTs showed that metformin had a neuroprotective effect compared to placebo. Some studies found negative or neutral effects for metformin use by people with diabetes; the potential mechanism of metformin-induced vitamin B12 deficiency is discussed.

Conclusions: Metformin should continue to be used as a first line therapy for diabetes in patients at risk of developing dementia or Alzheimer's disease. The use of metformin by individuals without diabetes for the prevention of dementia is not supported by the available evidence.
\end{abstract}

Keywords: Alzheimer's disease, cognitive dysfunction, dementia, diabetes mellitus, meta-analysis, metformin, systematic review

\section{INTRODUCTION}

${ }^{*}$ Correspondence to: Jared M. Campbell, Joanna Briggs Institute, Faculty of Health and Medical Sciences, The University of Adelaide, South Australia. Tel.: +61 0411455435; E-mail: campbel.jm@gmail.com.
The global prevalence of dementia was 35.6 million people in 2010, affecting 5-7\% of people aged 60 years or over [1]. The most common form of 
dementia is Alzheimer's disease (AD), which represents $50-75 \%$ of cases [2]. Due to the aging population, the increasing prevalence of dementia is not expected to decline without a major breakthrough in prevention. Another disease with a troublingly high prevalence is diabetes, which affects $5-9 \%$ of the overall population [3,4], and over a quarter of those aged $\geq 65$ years [4]. Diabetes is associated with the onset of dementia and $\mathrm{AD}[5]$; a meta-analysis of 28 longitudinal studies demonstrated that people with diabetes had a $73 \%$ increased risk of developing dementia and a $56 \%$ increased risk of developing AD compared to the general population.

The mechanism behind the association between diabetes and dementia is likely to be multifactorial with evidence supporting the involvement of chronic low-grade inflammation, oxidative stress, vascular effects, increased cerebral amyloid- $\beta$ peptides, hyperinsulinemia, brain insulin resistance, and the formation of advanced glycation end-products [6-8]. An influential factor is elevated blood glucose, which occurs as a direct consequence of diabetes and has been shown to cause impaired episodic memory even in people who do not have diabetes [9].

Metformin, a biguanide and first-line antihyperglycemic drug for type 2 diabetes, is an insulin sensitizer that reduces blood glucose by increasing glucose uptake into muscles while reducing liver gluconeogenesis through the activation of AMP-activated protein kinase (AMPK) [10]. The contemporary popularity of metformin as a therapy for diabetes stems from the UK prospective diabetes study (UKPDS), a multi-center, randomized controlled trial (RCT) with a median follow up of over 10 years carried out in overweight patients with type 2 diabetes [11]. It showed that intensive blood glucose control with metformin reduced the incidence of diabetes-related endpoints and all-cause mortality.

However, older people have been observed to be less likely than younger people to be receiving metformin $[12,13]$. This difference in prescribing patterns may be detrimental as metformin-use has been associated with reduced rates of dementia [14, 15] and improved cognitive function [16-18]. The clearest mechanism for metformin to act on the development of dementia in patients with diabetes is by preventing hyperinsulinemia which contributes to the formation of amyloid- $\beta$ plaques in the brain and the onset of AD [19]. However, the glucose lowering effects of metformin also reduce the formation of advanced glycation end-products [20] as well as inflammation and oxidative stress [21]. These processes are exacerbated by uncontrolled diabetes and have been linked to the development of dementia [22].

Interestingly, the effect of metformin on inflammation occurs independent of diabetes status [21]. Moreover, effects of metformin mimic caloric restriction [23] through activating AMPK. Both caloric restriction and metformin have been found to slow the aging process in animals [24, 25], and caloric restriction can improve memory in older people [26]. Metformin could therefore be able to prevent or delay the development of dementia beyond its effect on diabetes control. Metformin's potential as a geroprotective agent is supported by a recent systematic review which found that metformin reduced mortality and diseases of aging (cardiovascular disease and cancer) independently of its effect on diabetes control and in comparison to patients who did not have diabetes [27].

Conversely, some evidence suggests that metformin could damage cognitive health. A cell culture model found that it increased the formation of amyloid- $\beta$ [28], while one observational study found that its use was associated with an increased rate of AD [29] and another found metformin lowered cognitive function [30]. The latter study suggested that this effect could be due to vitamin $\mathrm{B}_{12}$ deficiency, potentiated by metformin, which causes cognitive impairment [31, 32].

The unresolved question as to whether treatment with metformin safeguards or harms cognitive health in older people impedes clinical practice in this area. Therefore, this systematic review aims to identify and synthesize the best available evidence on the effect of metformin on the risk, progression and severity of $\mathrm{AD}$ and any other forms of dementia, as well as its effect on measures of cognitive ability or impairment.

\section{METHODS}

This systematic review was carried according to an a priori registered protocol [33].

\section{Inclusion criteria}

Eligibility criteria for study inclusion were as follows: Population: Any study on human participants was eligible for inclusion. Although the majority of studies were on older people with diabetes, that was not a criterion for inclusion. Exposure: Studies in which participants received metformin at any dose for any duration were included. Comparator: Any study 
that included a control group in which participants were not being treated with metformin was eligible for inclusion. This included people not receiving any therapy as well as those receiving other treatments for diabetes. Outcomes: Studies that investigated risk (or incidence), severity or progression of dementia (including subtypes of dementia such as AD or vascular dementia) as well as cognitive impairment or performance (whether investigated as a continuous measure or dichotomized using threshold values) were eligible for inclusion. Types of studies: Any controlled experimental studies or observational study designs (including cohort, case-control or crosssectional studies) were eligible for inclusion in this systematic review.

\section{Search strategy}

PubMed, Embase, and PsycInfo were searched for published literature while the International Clinical Trials Registry Platform, ProQuest Dissertations and Theses Global, and OpenThesis were searched for "unpublished" data. No date restrictions were applied, however only English language articles were eligible for inclusion. Searching was carried out in May 2017 (Supplementary Material 1). Title and abstract screening was followed by the retrieval of potentially relevant full-texts which were compared to the inclusion criteria to identify eligible studies. The reference lists of included papers were reviewed for additional studies.

\section{Assessment of methodological quality and data extraction}

Critical appraisal was carried in duplicate by independent reviewers using the standardized Joanna Briggs Institute (JBI) appraisal checklists for experimental, cohort, case control, and cross-sectional studies [34] with consensus reached through discussion between reviewers. Studies were eligible for inclusion if they met $>50 \%$ of quality criteria. Data was extracted using a template that included fields for study methodology, study design, inclusion criteria, data source, country, exposure, comparator, sample size/events, follow up, outcome(s), outcome data, and statistical adjustments. Attempts to contact corresponding authors by email where additional data was needed were unsuccessful: in these cases, findings have been summarized narratively.

\section{Data synthesis}

Where possible, odds ratios (ORs) were pooled using the inverse variance method with a random effects model from RevMan (Review Manager, [Computer program]. Version 5.3. Copenhagen: The Nordic Cochrane Centre, The Cochrane Collaboration, 2014). Maximally adjusted data were included in all analyses. Longitudinal data was converted to hazard ratios (HRs) using the methods described by Tierney et al. [35]. For one study that reported OR and showed that their incidence ratio was constant [36], OR was substituted for HR which could not otherwise be calculated. Heterogeneity was assessed using the $\chi^{2}$ and $\mathrm{I}^{2}$ tests. Analysis of publication bias was planned, but too few studies $(<10)$ were found per outcome. Sensitivity analyses have been performed based on control groups utilized, diagnostic criteria and to identify sources of heterogeneity.

\section{RESULTS}

The initial search returned 862 citations which was reduced to 746 following the removal of duplicates. Twenty-three studies were identified after review of the titles and abstracts. Full-texts were retrieved and a further six studies were excluded for not including the relevant population [37], exposure [38-40], comparator [41], or outcome [42]. A further three studies were excluded on the basis of scoring $\leq 50 \%$ on critical appraisal [17, 43, 44], leaving 14 included studies (Fig. 1). Most included papers were observational

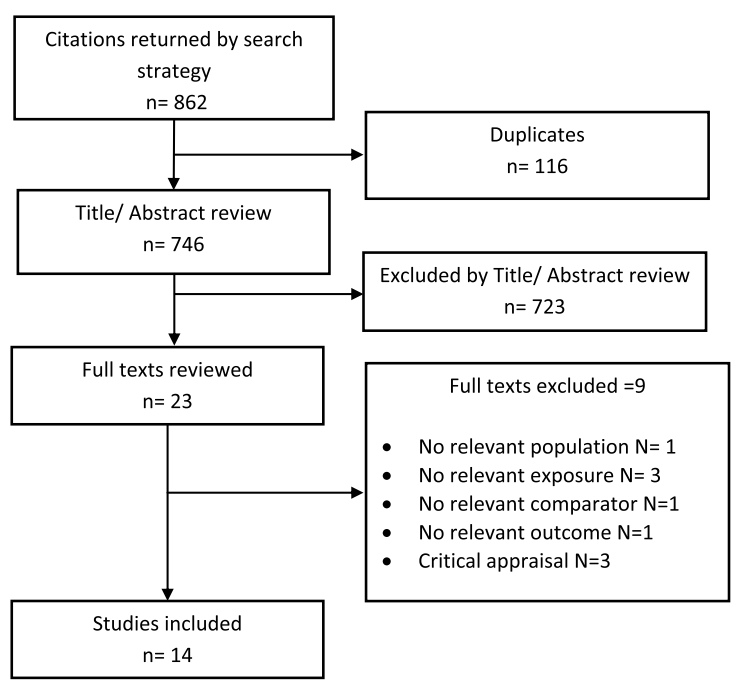

Fig. 1. PRISMA flow chart. 
study designs, the majority being cohort studies [14, $15,36,45-48]$, as well as four cross-sectional [16, $30,49,50]$ and one case-control study [29]. Additionally, two RCTs were identified and included [51, 52]. Studies were carried out in Taiwan $[14,15$, 47, 49], USA [36, 50, 52], Australia [30, 46], Germany [45], Singapore [48], UK [29], China [51], and Japan [16]. Three of the studies carried out in Taiwan drew their data from the National Health Insurance Research Database, but either investigated different outcomes or utilized separate cohorts [14, 15, 47]. Sample sizes varied from 114,199 [15] to 27 [49] and follow up varied from 24 weeks [51] to 9 years [36] (Table 1). Additional details on the covariates which were adjusted for in statistical analyses are included in Supplementary Table 1. Critical appraisal of the included studies showed that studies were rigorous in most areas (Supplementary Table 2). Exceptions were that the cohort studies had potentially impactful differences between groups at baseline and did not provide sufficient detail on loss-to-follow-up, neither of the RCTs reported whether assessors were blind, and most of the cross-sectional studies did not describe how metformin exposure was assessed.

\section{Incidence and prevalence of dementia}

Three studies reported cross-sectional prevalence data which could be pooled in meta-analysis. Liccini et al. [50] assessed cognitive dysfunction using rapid cognitive screen score $\leq 7$ (a score of $\leq 5$ would indicate dementia [53]), Yokoyama et al. [16] used the Mini-Mental State Examination (MMSE) and classed scores $<24$ as indicating abnormal cognition, while $\mathrm{Ng}$ et al. [48] also used the MMSE but with a cut-off of $\leq 23$. All three studies included patients with diabetes who were not being treated with metformin as their control group. Meta-analysis showed that using metformin for diabetes management was associated with a lower likelihood of having developed cognitive impairment $(\mathrm{OR}=0.55,95 \% \mathrm{CI} 0.38$ to $0.78 ; p=0.0009$, Fig. 2). When the analysis was restricted to patients who would be classed as having dementia by the tool used (Yokoyama et al. and $\mathrm{Ng}$ et al.) results were not meaningfully impacted $(\mathrm{OR}=0.56,95 \% \mathrm{CI} 0.37$ to $0.85, p=0.007)$. A further cross-sectional study [30] could not be included in the meta-analysis due to incompatible design. It was carried out in a cohort constructed from patients who were cognitively intact, had mild cognitive impairment, or $\mathrm{AD}$ (but not patients with other forms of dementia). Here, metformin use was associated with worse cognitive performance (based on ordinal analysis after patients were classified as "most impaired" (MMSE <18), "mildly impaired" (MMSE 18-23), "minimally impaired" MMSE 24-27) or "not impaired" (MMSE 28-30)). The effect was attenuated and non-significant when adjustments for vitamin $\mathrm{B}_{12}$ levels were made.

Six cohort studies investigated the effect of metformin on the longitudinal incidence of dementia compared to patients with diabetes not taking metformin $[14,15,36,45,47,48]$. There was methodological heterogeneity due to the differences in the control groups utilized which included patients with diabetes receiving sulphonylurea [14], no drug therapy [15], or any patients with diabetes not receiving metformin [14, 36, 45, 47, 48] (Table 1). Periods of follow-up also differed; however, the use of incidence ratios should limit the impact of this source of variation. All studies had the clinical diagnosis of dementia or $\mathrm{AD}$ as their outcome except $\mathrm{Ng}$ et al. [48] who utilized MMSE score. Meta-analysis of these studies showed that patients with diabetes taking metformin had decreased risk of developing dementia or $\mathrm{AD}$ compared to other patients with diabetes ( $\mathrm{HR}=0.76,95 \% \mathrm{CI} 0.60$ to $0.97 ; p=0.03$, Fig. 3). When meta-analysis was restricted to studies which had adjusted their results for the effect of metformin diabetes management $[36,48]$, metformin-use still resulted in a significant reduction in incidence of dementia $(\mathrm{HR}=0.50,95 \%$ CI 0.27 to $0.91 ; p=0.02)$.

Several studies reported additional longitudinal data that could not be included in the meta-analyses. Wang et al. [36] used advanced modeling to subdivide their cohort into patients with different levels of risk for developing age related diseases including a high cancer risk class, high cardiovascular disease risk class, high frailty risk class, and a healthy class (who had low risk of developing any of these age-related diseases). The effect of metformin on dementia incidence was observed in the high frailty risk class and the healthy class (which was included in the meta-analysis due to being largest and most generalizable), but was not significant in the other two groups. Cheng et al. [14] also compared the results of patients treated with thiazolidinedione to patients treated with metformin and found an even larger effect than was observed in comparison to sulphonylurea (which was included in the meta-analysis due to having the larger sample size and being a more common therapy). $\mathrm{Ng}$ et al. [48] reported analyses where they subdivided their cohort into patients who had received metformin for 6 years or less before 
Table 1

Characteristics of included studies

\begin{tabular}{|c|c|c|c|c|c|}
\hline Study & Exposure & Comparator & Population & N/events and Follow up & Outcome(s) \\
\hline Cheng [14] & $\begin{array}{l}\text { New onset T2DM who used } \\
\text { metformin only (never in } \\
\text { combination, and never insulin) }\end{array}$ & $\begin{array}{l}\text { New onset } \\
\text { T2DM who used } \\
\text { TZD only } \\
\text { OR } \\
\text { Sulph only }\end{array}$ & $\begin{array}{l}\text { Taiwan. Cohort. Aged } 65 \text { and older, dementia free and T2DM } \\
\text { free }\end{array}$ & $\begin{array}{l}\text { Metformin }=1,033 / 39 \\
\text { TZD }=28 / 4 \\
\text { Sulph }=796 / 40 \\
6 \text { years (median time to T2DM was } 2.4 \\
\text { years) }\end{array}$ & $\begin{array}{l}\text { Development of dementia (at } \\
\text { least two records of dementia } \\
\text { diagnosis in the same year) after } \\
\text { the development of diabetes }\end{array}$ \\
\hline Heneka [45] & Metformin-use & $\begin{array}{l}\text { Diabetes no } \\
\text { metformin, } \\
\text { OR } \\
\text { No-diabetes }\end{array}$ & $\begin{array}{l}\text { Germany. Cohort. Aged } 60 \text { and older, dementia free, not } \\
\text { receiving insulin }\end{array}$ & $\begin{array}{l}\text { Metformin }=67,822 \text { (person years) } / 1,478 ; \\
\text { No-metformin }=122,036 \text { (person } \\
\text { years) } / 3,854 ; \text { No-diabetes }=443,559 \\
(\text { person years) } / 7,845 \\
5 \text { years }\end{array}$ & $\begin{array}{l}\text { Verified dementia diagnosis } \\
\text { according to ICD-10 }\end{array}$ \\
\hline Herath [46] & Metformin-use & $\begin{array}{l}\text { Other diabetes } \\
\text { medication }\end{array}$ & $\begin{array}{l}\text { Australia. Cohort. Aged } 65-69 \text {, with no history of stroke, } \\
\text { epilepsy, or dementia. Receiving diabetes treatment, excluding } \\
\text { DPP4 inhibitors, glitazones, or insulin monotherapy }\end{array}$ & Metformin $=49 / \mathrm{Na}$; Other $=\mathrm{NR}$ & $\begin{array}{l}\text { MMSE, SDMT, Imm Rec, STW, } \\
\text { Digit Back, Trail A, Trail B, } \\
\text { PPEG (both hands), SRT, CRT }\end{array}$ \\
\hline Hsu [15] & Metformin monotherapy & $\begin{array}{l}\text { T2DM but no } \\
\text { diabetes drug } \\
\text { OR } \\
\text { No-diabetes }\end{array}$ & Taiwan. Cohort. Aged 50 or older, dementia free & $\begin{array}{l}\text { Metformin = 1,864/66; No } \\
\text { drug = 10,519/434; } \\
\text { No-diabetes = 101,816/3376 } \\
7 \text { years }\end{array}$ & $\begin{array}{l}\text { Incident dementia (at least two } \\
\text { records of dementia diagnosis in } \\
\text { the same year) }\end{array}$ \\
\hline Huang [47] & $\begin{array}{l}\text { Metformin monotherapy } \\
\text { OR } \\
\text { Metformin combination therapy }\end{array}$ & $\begin{array}{l}\text { Other diabetes } \\
\text { therapy }\end{array}$ & $\begin{array}{l}\text { Taiwan. Cohort. Newly diagnosed diabetes patients who had } \\
\text { not been previously diagnosed with AD }\end{array}$ & $\begin{array}{l}\text { Overall }=71,433 / 346 \\
5.5 \text { years }\end{array}$ & $\begin{array}{l}\text { AD (ICD-9-CM code: } 331.0) \\
\text { based on history, physical } \\
\text { examination, imaging and } \\
\text { MMSE. }\end{array}$ \\
\hline Imfeld [29] & $\begin{array}{l}\text { Metformin: } 1-9,10-29 \text {, } \\
30-59, \geq 60 \text { prescriptions } \\
\text { OR } \\
\text { Metformin monotherapy: } 1-9 \text {, } \\
10-29, \geq 30 \text {. }\end{array}$ & $\begin{array}{l}\text { No metformin } \\
\text { (other diabetes) } \\
\text { OR } \\
\text { No-diabetes }\end{array}$ & UK. Cohort. Individuals aged 65 and older & $\begin{array}{l}\text { Metformin: } 1-9=158 / 65,10-29=165 / 80 \text {, } \\
30-59=164 / 63, \geq 60=147 / 76 \text {. } \\
\text { Metformin monotherapy: } 1-9=58 / 27 \text {, } \\
10-29=50 / 25, \geq 30=49 / 20 \\
\text { No metformin }=13,538 / 6,802 . \\
\text { No-diabetes }=12,855 / \mathrm{NR} \\
\text { NR }\end{array}$ & $\begin{array}{l}\text { AD diagnosis (not including } \\
\text { other forms of dementia) }\end{array}$ \\
\hline
\end{tabular}


Table 1

(Continued)

\begin{tabular}{|c|c|c|c|c|c|}
\hline Study & Exposure & Comparator & Population & N/events and Follow up & Outcome(s) \\
\hline $\mathrm{Ng}[48]$ & $\begin{array}{l}\text { Metformin in the year before } \\
\text { baseline } \\
\text { OR } \\
\text { Metformin } \leq 6 \text { years before } \\
\text { baseline } \\
\text { OR } \\
\text { Metformin }>6 \text { years before } \\
\text { baseline }\end{array}$ & $\begin{array}{l}\text { No metformin } \\
\text { use in the year } \\
\text { before baseline }\end{array}$ & $\begin{array}{l}\text { Singapore. Cohort. Aged } 55 \text { years or older without severe } \\
\text { mental or physical disabilities with diabetes. }\end{array}$ & $\begin{array}{l}\text { Metformin }=204 / \mathrm{NR} ; \text { Non } \\
\text { users }=161 / \mathrm{NR} \\
3.9 \text { years }\end{array}$ & $\begin{array}{l}\text { Cognitive impairment (MMSE } \\
\leq 23 \text { ) and mean MMSE }\end{array}$ \\
\hline Wang [36] & $\begin{array}{l}\text { Metformin-use } \geq 180 \text { days of } \\
\text { prescription }\end{array}$ & $\begin{array}{l}\text { No days of } \\
\text { metformin } \\
\text { prescription }\end{array}$ & $\begin{array}{l}\text { USA. Cohort. Male veterans aged } \geq 65 \text { with T2DM free from } \\
\text { age-related comorbidities (CVD, cancer, depression, dementia, } \\
\text { frailty related diseases). Divided into Health class, Cancer risk } \\
\text { class, CVD risk class, Frailty risk class. }\end{array}$ & $\begin{array}{l}\text { Overall: Healthy }=22,841 / \mathrm{NR} \text {, Cancer } \\
\text { risk }=4,669 / \mathrm{NR}, \mathrm{CVD} \text { risk }=6,697 / \mathrm{NR} \text {, } \\
\text { Frailty risk }=6,697 / \mathrm{NR} \\
9 \text { years }\end{array}$ & $\begin{array}{l}\text { Dementia diagnosis } \\
\text { (ICD9:290.xx) }\end{array}$ \\
\hline Guo [51] & $\begin{array}{l}\text { Metformin (starting dose } 0.5 \mathrm{~g} \\
\text { per tablet, two tablets a day, } \\
\text { increasing up to } 2.0 \mathrm{~g} / \text { day to } \\
\text { achieve blood glucose control) }\end{array}$ & $\begin{array}{l}\text { Placebo } \\
\text { (vitamin C tablet } \\
\text { with the same } \\
\text { appearance) }\end{array}$ & $\begin{array}{l}\text { China. RCT. Patients aged between } 40 \text { and } 65 \text { with T2DM and } \\
\text { depression who were not using insulin or other anti-diabetic } \\
\text { medications, and had no serious diabetes complications, history } \\
\text { of substance abuse or dependence, severe heart failure or other } \\
\text { abnormal laboratory findings. }\end{array}$ & $\begin{array}{l}\text { Metformin }=29 / \mathrm{Na} ; \text { Placebo }=29 / \mathrm{Na} \\
24 \text { weeks }\end{array}$ & Wechsler Memory Scale Revised \\
\hline $\begin{array}{l}\text { Luchsinger } \\
{[52]}\end{array}$ & $\begin{array}{l}\text { Metformin }(1000 \mathrm{mg} \text { twice per } \\
\text { days was the goal although not all } \\
\text { patients tolerated) }\end{array}$ & Placebo & $\begin{array}{l}\text { USA. RCT. Participants were aged } 55 \text { to } 90 \text { years with } \\
\text { amnestic mild cognitive impairment without treated diabetes } \\
\text { and a BMI of } \geq 25\end{array}$ & $\begin{array}{l}\text { Metformin }=40 / \mathrm{Na} \text {, Placebo }=40 / \mathrm{Na} \\
\text { (ITT) }\end{array}$ & $\begin{array}{l}\text { Primary: Total recall of the } \\
\text { Bushcke SRT, ADAS-cog }\end{array}$ \\
\hline Huang [49] & Metformin-use & $\begin{array}{l}\text { Never use of } \\
\text { metformin }\end{array}$ & $\begin{array}{l}\text { Taiwan. Cross-sectional. Adults with T2DM taking antidiabetic } \\
\text { drugs with no neuropsychological or medical conditions that } \\
\text { can alter mental status, alcohol or substance abuse, use of } \\
\text { hypnotics, brain tumor, autoimmune disease, AIDS, pregnancy, } \\
\text { or history of head trauma with loss of consciousness. }\end{array}$ & Metformin $=18 / \mathrm{NR}$, No use $=9 / \mathrm{NR}$ & MMSE score \\
\hline Liccini [50] & Metformin-use & $\begin{array}{l}\text { Non-use of } \\
\text { metformin }\end{array}$ & $\begin{array}{l}\text { USA. Cross-sectional. Patients with DM aged } 50 \text { to } 90 \text { with } \\
\text { rapid cognitive screen score } 5 \text { or greater }\end{array}$ & $\begin{array}{l}\text { Metformin }=80 / \mathrm{NR}, \\
\text { Non-metformin }=80 / \mathrm{NR}\end{array}$ & $\begin{array}{l}\text { Cognitive dysfunction (evaluated } \\
\text { using RCS } \leq 7 \text { ) }\end{array}$ \\
\hline Moore [30] & Use of metformin & $\begin{array}{l}\text { Non-use of } \\
\text { metformin }\end{array}$ & $\begin{array}{l}\text { Australia. Cross-sectional. Participants had T2DM and AD, } \\
\text { MCI or who were cognitively intact were included. Patients } \\
\text { with stroke or neurodegenerative disorders other than AD } \\
\text { (including frontotemporal dementia, Parkinson's disease, } \\
\text { dementia with Lewy bodies or mixed dementia) were excluded. }\end{array}$ & $\begin{array}{l}\text { Metformin }=35 / \mathrm{NR}, \text { No } \\
\text { Metformin }=91 / \mathrm{NR}\end{array}$ & $\begin{array}{l}\text { Cognitive performance: Most } \\
\text { impaired (MMSE <18), mildly } \\
\text { impaired (MMSE 18-23), } \\
\text { minimally impaired (MMSE } \\
\text { 24-27), not impaired (MMSE } \\
\text { 28-30). Mean MMSE score. }\end{array}$ \\
\hline $\begin{array}{l}\text { Yokoyama } \\
{[16]}\end{array}$ & Use of metformin & $\begin{array}{l}\text { Non-use of } \\
\text { metformin }\end{array}$ & $\begin{array}{l}\text { Japan. Cross-sectional. Patients age } 50 \text { years and over with } \\
\text { T2DM and with no prior diagnosis of dementia }\end{array}$ & Overall $=1,323 / 79$ & $\begin{array}{l}\text { Abnormal cognition (MMSE } \\
<24 \text { ) }\end{array}$ \\
\hline
\end{tabular}

Digit Span Backward test: Imm Rec, immediate recall; ITT, intention to treat; MCI, mild coonitive impairment; MMSE, Mini-Mental State Examination; Na, Not applicable; NR, Not reported; PPEG, Purdue Pegboard Test; RCS, Rapid Cognitive Screen; RCT, randomized controlled trial; SDMT, Symbol Digit Modalities Test; SRT, Selective Reminding Test; STW, Spot-the-Word task; Sulph, sulphonylurea; T2DM, type 2 diabetes mellitus; Trail A/B, Trail Making Test A/B; TZD, thiazolidinedione. 


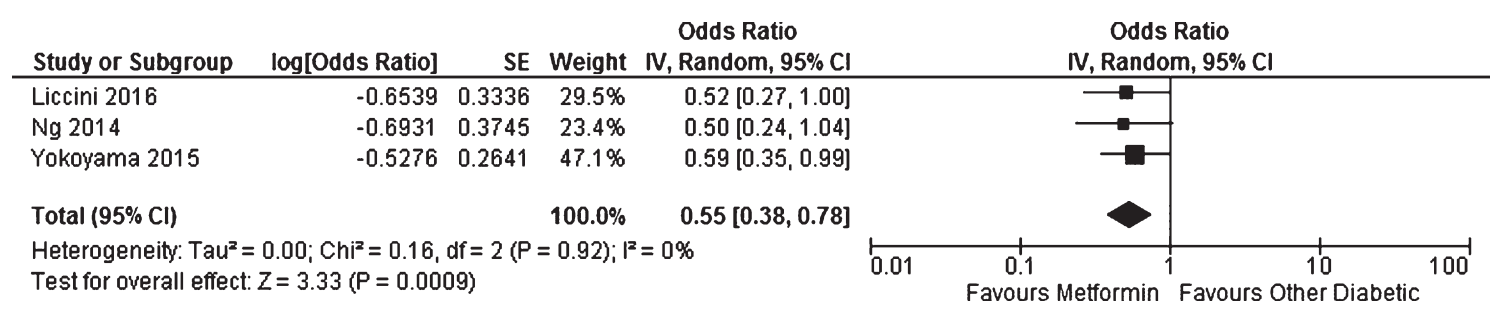

Fig. 2. Meta-analysis of the likelihood of having cognitive impairment in patients with diabetes receiving metformin compared to other patients with diabetes.

$\begin{array}{lrrrrrr}\text { Study or Subgroup } & \text { log[Hazard Ratio] } & \text { SE } & \text { Weight } & \begin{array}{c}\text { Hazard Ratio } \\ \text { IV, Random, 95\% Cl }\end{array} & \text { Hazard Ratio } \\ \text { IV, Random, 95\% Cl }\end{array}$

Fig. 3. Meta-analysis of the incidence of dementia or Alzheimer's disease in patients with diabetes receiving metformin compared to other patients with diabetes.

baseline and those who had received it for more than 6 years and found that the effect of metformin on dementia incidence was only seen in the patients with long-term use. Similarly, Hsu et al. [15] divided their cohort into patients who had had diabetes for $>7$ years, 4-7 years, and $\leq 3$ years. Exclusive metformin users had a significant reduction in dementia incidence in the long-term cohort $(\mathrm{HR}=0.62,95 \% \mathrm{CI}$ 0.43 to $0.91, p<0.05$ ); however, the effect was nonsignificant in the second cohort $(\mathrm{HR}=0.64,95 \% \mathrm{CI}$ 0.38 to 1.08$)$ and much reduced in those with shortest use $(\mathrm{HR}=0.81,95 \% \mathrm{CI} 0.48$ to 1.36$)$. Finally, the case-control study [29] investigated the risk of $\mathrm{AD}$ (excluding other dementias) in patients who had received 1-9, 10-29, 30-59, and $\geq 60$ prescriptions for metformin compared to patients with diabetes who had not been treated with metformin. Unadjusted analyses showed significant reductions in the risk of $\mathrm{AD}$ for patients who received $1-9(\mathrm{OR}=0.68,95 \% \mathrm{CI}$ 0.49 to 0.94$)$ or $30-59(\mathrm{OR}=0.61,95 \% \mathrm{CI} 0.45$ to 0.84 ) prescriptions (and non-significant effects for $10-29$ and $\geq 60$ prescriptions which had ORs equal to 0.93 and 1.06 , respectively) while adjusted analyses showed significant increases in risk of AD for $10-29(\mathrm{OR}=1.47,95 \% \mathrm{CI} 1.03$ to 2.09$)$ and $\geq 60$ prescriptions ( $\mathrm{OR}=1.71,95 \% \mathrm{CI} 1.12$ to 2.60$)$ with non-significant effects for 1-9 and 30-59 prescriptions $(\mathrm{OR}=1.08$ and 0.99 , respectively).
Two studies carried out longitudinal analyses to investigate the incidence of dementia in patients with diabetes using metformin compared to people who did not have diabetes (and were therefore not taking metformin) [15, 45]. The results of a meta-analysis showed a non-significant increased risk of developing dementia in the people with diabetes taking metformin ( $\mathrm{HR}=1.42,95 \%$ CI 0.95 to $2.11, p=0.08$, Fig. 4). Imfeld et al. [29] compared the prevalence of $\mathrm{AD}$ in patients with diabetes who had received $1-9,10-29$, and $\geq 30$ prescriptions of metformin as monotherapy to non-diabetic people, but did not find any significant effects.

\section{Cognitive performance}

The two RCTs both compared the performance of patients treated with metformin to those who received a placebo. Guo et al. [51] showed that in patients with diabetes who also had depression who were not receiving insulin or any other antihyperglycemic medication, metformin over 24 weeks significantly improved cognitive performance on all items of the Wechsler Memory Scale-revised (Verbal memory index $=22.19 p<0.001$, Visual memory index $=10.53 p<0.01$, General memory index $=4.27 p<0.05$, Attention and concentration $p<0.01$, Delayed memory index $=19.84 p<0.001$ ). 


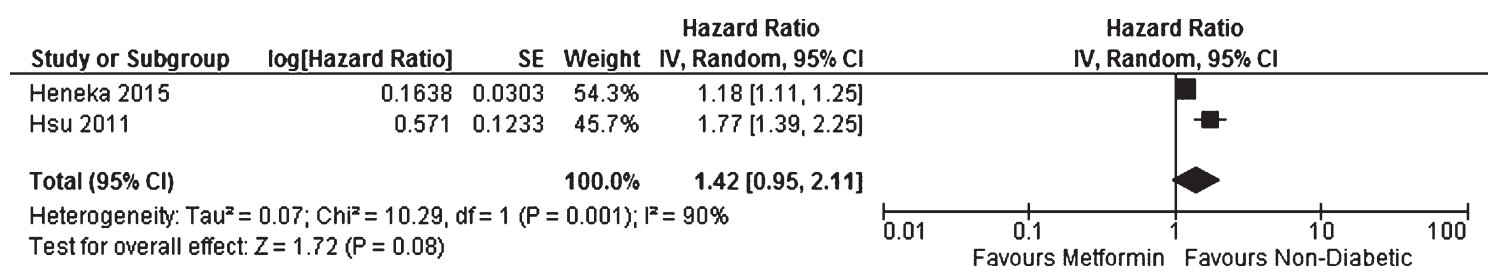

Fig. 4. Meta-analysis of the incidence of dementia or Alzheimer's disease in patients with diabetes receiving metformin compared to people without diabetes.

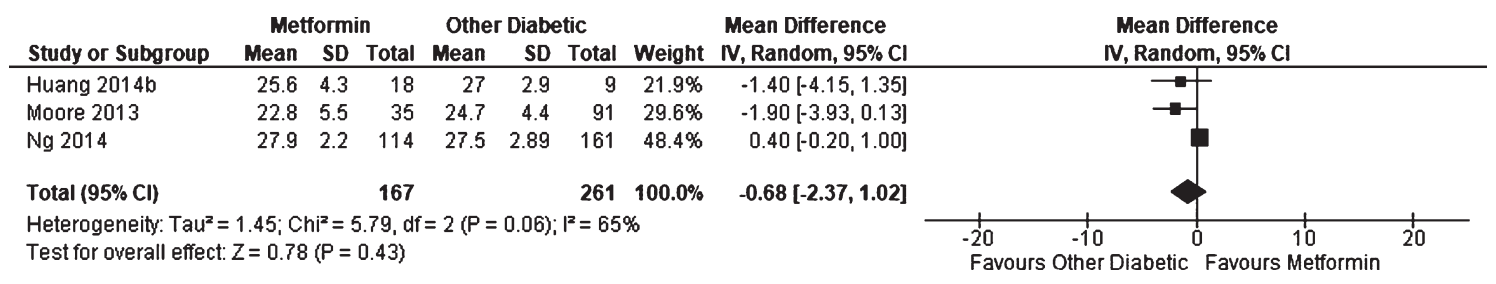

Fig. 5. Weighted mean difference for Mini-Mental State Examination score in patients with diabetes receiving metformin compared to other patients with diabetes.

Interestingly improved performance correlated with improved depression which in turn correlated with improved HbA1c. The second RCT investigated the effect of 12 months of metformin therapy in patients with amnestic mild cognitive impairment and body mass index $(\mathrm{BMI}) \geq 25$, but no diagnosed diabetes [52]. Change from baseline in Selective Reminding Task significantly favored the metformin treated patients (Unit change in test: Metformin $=9.5 \pm 6.1$; Placebo $=5.4 \pm 6.1, p=0.05$ ); however, changes in the other primary outcome, Alzheimer's Disease Assessment Scale-Cognitive were non-significant (Metformin $=-0.5 \pm 4.1 ; \quad$ Placebo $=-1.4 \pm 4.1, \quad p=$ 0.34). Secondary measures included the Clinical Global Impression of Change for mild cognitive impairment, logical memory II delayed paragraph recall subtest of the Wechsler Memory Scale Revised, MMSE, Neuropsychiatric Inventory Questionnaire, and digit span backwards; however, no significant effects were observed.

Three observational studies [30, 48, 49] reported on average performance on the MMSE for patients with diabetes receiving metformin compared to other patients with diabetes; however, no significant effect was found $(\mathrm{WMD}=-0.68,95 \% \mathrm{CI}-2.37$ to 1.02 ; $p=0.43$, Fig. 5). Results were not adjusted for differences in patient characteristics. One additional cohort study, Herath et al. [46], reported that metformin users showed significantly better performance at baseline with the digit span backwards test compared to other patients with diabetes; however, there was no change associated with metformin-use at 4 years follow up. Other measures included MMSE, Symbol Digit Modalities Test, Immediate recall, Spot-the-Word task, Trail Making Test A and B, Purdue Pegboard Test, Selective Reminding Test, and Choice Reaction Time, but no differences were found.

\section{DISCUSSION}

This systematic review found that the available evidence provides some support for metformin having a protective effect against dementia in people who are taking it for the management of diabetes. Meta-analysis of cross-sectional studies showed significantly reduced prevalence of cognitive impairment and dementia amongst users of metformin compared to other patients with diabetes. One study, Moore et al., which could not be included in the meta-analysis, contradicted this result with a significant finding of worse cognitive performance in metformin users which was mitigated by adjustment for vitamin $B_{12}$ levels [30]. Interestingly, this study was carried out in Australia where average vitamin $\mathrm{B}_{12}$ concentrations have been reported at lower levels than the USA [54], Japan [54], and Singapore [55] where the studies included in the metaanalysis - which homogenously provided evidence of a protective effect-were carried out $[16,48,50]$. Vitamin $B_{12}$ deficiency can be induced by metformin [31] and has been linked to cognitive impairment [32]. This suggests that metformin may exert a dual effect on cognitive health; counteracting the 
neurodegenerative effects of diabetes, but harming patients who are vulnerable to vitamin $B_{12}$ deficiency. Evidence for this hypothesis is largely circumstantial, however, and requires direct investigation.

Meta-analysis of the included longitudinal studies reinforces metformin's potential for neuroprotection amongst patients with diabetes by showing that its use was also associated with significantly reduced incidence of dementia and $\mathrm{AD}$. Although more studies were included in this meta-analysis, the control groups utilized varied considerably. Additionally, once again there was one study, Imfeld et al. [29], that found a significant association between metformin-use and AD. The findings of this study were complicated by the fact that no dose response effect was apparent, and statistical adjustment, which was performed without assessing multicollinearity, changed crude findings of significant protection to neutral results, and neutral results to significant findings of harm. Interestingly, this negative finding was made in the UK, where vitamin $B_{12}$ deficiency among older people has been reported to exceed $30 \%$ [54]. Further supporting the hypothesis that metformin has an overall neuroprotective role in patients with diabetes but can have a detrimental effect in those vulnerable to $B_{12}$ deficiency is the fact that the statistical heterogeneity in this meta-analysis was entirely due to the inclusion of Heneka et al. [45]; its removal from the meta-analysis transformed the $\mathrm{I}^{2}$ value (a measure of magnitude of heterogeneity) from $63 \%$ to $1 \%$. In their German cohort, where vitamin $\mathrm{B}_{12}$ levels have been reported at even lower levels than the UK [54], Heneka et al. found close to no relationship between metformin and dementia incidence. An additional longitudinal study that was published after the search phase of the review was completed reported an apparent detrimental effect for metformin on the incidence of dementia in Taiwanese patients with type 2 diabetes [56]. Unfortunately, we could not locate any studies that investigated vitamin $\mathrm{B}_{12}$ levels in Taiwan.

A sensitivity analysis found that when data was adjusted for the level of diabetes control achieved the effect of metformin on dementia incidence remained significant. This analytic strategy has been used in the past to investigate whether geroprotective effects of metformin therapy may be due to reasons other than its effect on glycemic control [27, 57] and therefore potentially applicable to the non-diabetic population. However, in the meta-analysis where the incidence of dementia in patients with diabetes taking metformin was compared to individuals who did not have diabetes the result was a non-significant increase (Fig. 4). This finding does not rule out the possibility that metformin had a positive effect, but that it was masked by the detrimental influence of diabetes. One of the RCTs, Luchsinger et al. [52], included nondiabetic older people with amnestic mild cognitive impairment and found that over a year metformin produced a significant improvement in one measure of cognitive performance (Selective Reminding Task). However, there was no significant difference in several others. Additionally, the study cohort all had BMIs $\geq 25$, greatly increasing the likelihood that the effect produced by metformin was due to its effects on insulin resistance. Overall, the findings of this review provide only very weak support for the hypothesis that metformin could preserve cognitive health in people who do not have diabetes.

The other RCT, Guo et al. [51], also investigated the effect of metformin on measures of cognitive performance but in patients with diabetes (and depression) compared to patients who were not using any diabetes medication. It found that metformin-use significantly improved all measures of the Wechsler Memory Scale Revised. This finding that cognitive performance improved should be given greater weight than the meta-analysis of unadjusted observational data that found no significant effect of metformin on MMSE. Interestingly, its follow up period was just 24 weeks, whereas the two studies that examined length of metformin-use found that its neuroprotective effects appeared to emerge with longer-term use ( 8 and 6 years) [15, 48]. Luchsinger et al. [52] performed regression analyses which showed that the effects of metformin were greatest in younger patients. These findings suggest that metformin therapy is likely to be most effective when its use is begun early, although it can still be of benefit if begun after the onset of cognitive decline. This makes it most likely that metformin's main form of action is to reduce damage over time rather than acting directly on the brain as a nootropic. This could be confirmed in future research by comparing the cognitive function of older people taking metformin to those who had withdrawn for a short period.

Further research should include additional clinical trials with sufficient follow-up and sample sizes for meaningful event numbers to accumulate; the study by Luchsinger et al. had 12 months follow up and 80 participants, but only reported one dementia diagnosis in the control group [52]. Further clinical investigation of whether metformin can safeguard the cognitive health of people who do not have diabetes 
is warranted, but at this stage it should probably be restricted to those with the dementia risk factors of overweight, insulin resistance and/or metabolic syndrome [58]. Future observational studies should make use of propensity score matching, or at the least match for age and health status, to improve the validity of data by reducing baseline variability and, wherever possible, examine the interaction of metformin-use, vitamin $\mathrm{B}_{12}$ levels, and cognitive decline. Wang et al. [36] found that older people at risk of frailty experienced the greatest benefit from metformin-use, while other subgroups saw no significant improvement. Further investigation of which patient characteristics increase the likelihood of metformin exerting a neuroprotective effect could enable personalized medicine.

The main limitation of this systematic review is that it draws primarily from observational studies, which were heterogeneous in design and had baseline differences within their sometimes small cohorts. However, the findings of the meta-analyses of observational data are reinforced by experimental research. A previous systematic review on the effect of insulin sensitizers on dementia did not include these RCTs or the most recent observational studies, and its metaanalysis on metformin did not reach significance [59]. Additionally, some studies restricted inclusion to people with type 2 diabetes while others also included type 1 diabetes. Finally, there was no data available on the influence of metformin dose.

\section{Conclusions}

This review suggests that metformin prevents or delays the development of dementia in patients with diabetes. Conflicting findings could be explained by low levels of vitamin $B_{12}$ in the community being exacerbated by metformin-use. This supports vitamin $\mathrm{B}_{12}$ supplementation in patients taking metformin, particularly older adults. Evidence does not yet support the use of metformin by individuals without diabetes for prevention of dementia despite its apparent action as a general geroprotective agent [27].

\section{ACKNOWLEDGMENTS}

This work was supported by a grant from the Mason Foundation National Medical Program.

Authors' disclosures available online (https:// www.j-alz.com/manuscript-disclosures/18-0263r3).

\section{SUPPLEMENTARY MATERIAL}

The supplementary material is available in the electronic version of this article: http://dx.doi.org/ 10.3233/JAD-180263.

\section{REFERENCES}

[1] Prince M, Bryce R, Albanese E, Wimo A, Ribeiro W, Ferri CP (2013) The global prevalence of dementia: A systematic review and metaanalysis. Alzheimers Dement 9, 63-75 e62.

[2] Australian Institute of Health and Welfare (2012) Dementia in Australia. Australian Institute of Health and Welfare, Canberra.

[3] Australian Bureau of Statistics (2012) Australian Health Survey: First Results, 2011-12. ABS, Canberra.

[4] Centers for Disease Control and Prevention (2014) National Diabetes Statistics Report: Estimates of Diabetes and Its Burden in the United States, 2014. US Department of Health and Human Services, Atlanta.

[5] Gudala K, Bansal D, Schifano F, Bhansali A (2013) Diabetes mellitus and risk of dementia: A meta-analysis of prospective observational studies. J Diabetes Investig 4, 640-650.

[6] Ahtiluoto S, Polvikoski T, Peltonen M, Solomon A, Tuomilehto J, Winblad B, Sulkava R, Kivipelto M (2010) Diabetes, Alzheimer disease, and vascular dementia: A population-based neuropathologic study. Neurology $\mathbf{7 5}$, 1195-1202.

[7] Craft S (2007) Insulin resistance and Alzheimer's disease pathogenesis: Potential mechanisms and implications for treatment. Curr Alzheimer Res 4, 147-152.

[8] Haus JM, Kashyap SR, Kasumov T, Zhang R, Kelly KR, Defronzo RA, Kirwan JP (2009) Plasma ceramides are elevated in obese subjects with type 2 diabetes and correlate with the severity of insulin resistance. Diabetes $\mathbf{5 8}$, 337-343.

[9] Rolandsson O, Backestrom A, Eriksson S, Hallmans G, Nilsson LG (2008) Increased glucose levels are associated with episodic memory in nondiabetic women. Diabetes $\mathbf{5 7}$, 440-443.

[10] Zhou G, Myers R, Li Y, Chen Y, Shen X, Fenyk-Melody J, Wu M, Ventre J, Doebber T, Fujii N, Musi N, Hirshman MF, Goodyear LJ, Moller DE (2001) Role of AMP-activated protein kinase in mechanism of metformin action. J Clin Invest 108, 1167-1174.

[11] UK Prospective Diabetes Study (UKPDS) Group (1998) Effect of intensive blood-glucose control with metformin on complications in overweight patients with type 2 diabetes (UKPDS 34). UK Prospective Diabetes Study (UKPDS) Group. Lancet 352, 854-865.

[12] Clemens KK, Shariff S, Liu K, Hramiak I, Mahon JL, McArthur E, Garg AX (2015) Trends in antihyperglycemic medication prescriptions and hypoglycemia in older adults: 2002-2013. PLoS One 10, e0137596.

[13] Zaharan NL, Williams D, Bennett K (2014) Prescribing of antidiabetic therapies in Ireland: 10-year trends 2003-2012. Ir J Med Sci 183, 311-318.

[14] Cheng C, Lin CH, Tsai YW, Tsai CJ, Chou PH, Lan TH (2014) Type 2 diabetes and antidiabetic medications in relation to dementia diagnosis. J Gerontol A Biol Sci Med Sci 69, 1299-1305.

[15] Hsu CC, Wahlqvist ML, Lee MS, Tsai HN (2011) Incidence of dementia is increased in type 2 diabetes and reduced by 
the use of sulfonylureas and metformin. $J$ Alzheimers Dis 24, 485-493.

[16] Yokoyama H, Ogawa M, Honjo J, Okizaki S, Yamada D, Shudo R, Shimizu H, Sone H, Haneda M (2015) Risk factors associated with abnormal cognition in Japanese outpatients with diabetes, hypertension or dyslipidemia. Diabetol Int 6, 268-274.

[17] Zhou Y, Fang R, Liu LH, Chen SD, Tang HD (2015) Clinical characteristics for the relationship between type- 2 diabetes mellitus and cognitive impairment: A cross-sectional study. Aging Dis 6, 236-244.

[18] Stanojcic M, Chen P, Harrison RA, Wang V, Antonyshyn J, Zuniga-Pflucker JC, Jeschke MG (2014) Leukocyte infiltration and activation of the NLRP3 inflammasome in white adipose tissue following thermal injury. Crit Care Med 42, 1357-1364.

[19] Qiu WQ, Folstein MF (2006) Insulin, insulin-degrading enzyme and amyloid-beta peptide in Alzheimer's disease: Review and hypothesis. Neurobiol Aging 27, 190-198.

[20] Beisswenger P, Ruggiero-Lopez D (2003) Metformin inhibition of glycation processes. Diabetes Metab 29, 6S95-103.

[21] Cameron AR, Morrison VL, Levin D, Mohan M, Forteath C, Beall C, McNeilly AD, Balfour DJ, Savinko T, Wong AK, Viollet B, Sakamoto K, Fagerholm SC, Foretz M, Lang CC, Rena G (2016) Anti-inflammatory effects of metformin irrespective of diabetes status. Circ Res 119, 652-665.

[22] Luchsinger JA (2010) Type 2 diabetes, related conditions, in relation and dementia: An opportunity for prevention? $J$ Alzheimers Dis 20, 723-736.

[23] Handschin C (2016) Caloric restriction and exercise "mimetics": Ready for prime time? Pharmacol Res 103, 158-166.

[24] Anisimov VN, Berstein LM, Egormin PA, Piskunova TS, Popovich IG, Zabezhinski MA, Kovalenko IG, Poroshina TE, Semenchenko AV, Provinciali M, Re F, Franceschi C (2005) Effect of metformin on life span and on the development of spontaneous mammary tumors in HER-2/neu transgenic mice. Exp Gerontol 40, 685-693.

[25] Anderson RM, Shanmuganayagam D, Weindruch R (2009) Caloric restriction and aging: Studies in mice and monkeys. Toxicol Pathol 37, 47-51.

[26] Witte AV, Fobker M, Gellner R, Knecht S, Floel A (2009) Caloric restriction improves memory in elderly humans. Proc Natl Acad Sci U S A 106, 1255-1260.

[27] Campbell JM, Bellman SM, Stephenson MD, Lisy K (2017) Metformin reduces all-cause mortality and diseases of ageing independent of its effect on diabetes control: A systematic review and meta-analysis. Ageing Res Rev 40, 31-44.

[28] Chen Y, Zhou K, Wang R, Liu Y, Kwak YD, Ma T, Thompson RC, Zhao Y, Smith L, Gasparini L, Luo Z, Xu H, Liao FF (2009) Antidiabetic drug metformin (GlucophageR) increases biogenesis of Alzheimer's amyloid peptides via up-regulating BACE1 transcription. Proc Natl Acad Sci U $S$ A 106, 3907-3912.

[29] Imfeld P, Bodmer M, Jick SS, Meier CR (2012) Metformin, other antidiabetic drugs, and risk of Alzheimer's disease: A population-based case-control study. J Am Geriatr Soc 60, 916-921.

[30] Moore EM, Mander AG, Ames D, Kotowicz MA, Carne RP, Brodaty H, Woodward M, Boundy K, Ellis KA, Bush AI, Faux NG, Martins R, Szoeke C, Rowe C, Watters DA (2013) Increased risk of cognitive impairment in patients with diabetes is associated with metformin. Diabetes Care 36, 2981-2987.

[31] Chapman LE, Darling AL, Brown JE (2016) Association between metformin and vitamin B12 deficiency in patients with type 2 diabetes: A systematic review and meta-analysis. Diabetes Metab 42, 316-327.

[32] Moore E, Mander A, Ames D, Carne R, Sanders K, Watters D (2012) Cognitive impairment and vitamin B12: A review. Int Psychogeriatr 24, 541-556.

[33] Campbell JM, Stephenson MD, de Courten B, Chapman I, Bellman SM, Aromataris E (2017) Metformin and Alzheimer's disease, dementia and cognitive impairment: A systematic review protocol. JBI Database System Rev Implement Rep 15, 2055-2059.

[34] The Joanna Briggs Institute (2014) The Joanna Briggs Institute Reviewer's Manual: 2014 edition, Australia.

[35] Tierney JF, Stewart LA, Ghersi D, Burdett S, Sydes MR (2007) Practical methods for incorporating summary timeto-event data into meta-analysis. Trials $\mathbf{8}, 16$.

[36] Wang CP, Lorenzo C, Habib SL, Jo B, Espinoza SE (2017) Differential effects of metformin on age related comorbidities in older men with type 2 diabetes. $J$ Diabetes Complications 31, 679-686.

[37] Hill JL, Kobori N, Zhao J, Rozas NS, Hylin MJ, Moore AN, Dash PK (2016) Traumatic brain injury decreases AMP-activated protein kinase activity and pharmacological enhancement of its activity improves cognitive outcome. $J$ Neurochem 139, 106-119.

[38] Beard HA, Markides KS, Al Ghatrif M, Kuo YF, Raji MA (2010) Trends in diabetes medication use and prevalence of geriatric syndromes in older Mexican Americans from 1993/1994 to 2004/2005. Ann Pharmacother 44, 13761383.

[39] Domínguez RO, Marschoff ER, González SE, Repetto MG, Serra JA (2012) Type 2 diabetes and/or its treatment leads to less cognitive impairment in Alzheimer's disease patients. Diabetes Res Clin Pract 98, 68-74.

[40] Wu JH, Haan MN, Liang J, Ghosh D, Gonzalez HM, Herman WH (2003) Impact of antidiabetic medications on physical and cognitive functioning of older Mexican Americans with diabetes mellitus: A population-based cohort study. Ann Epidemiol 13, 369-376.

[41] Abbatecola AM, Lattanzio F, Molinari AM, Cioffi M, Mansi L, Rambaldi P, DiCioccio L, Cacciapuoti F, Canonico R, Paolisso G (2010) Rosiglitazone and cognitive stability in older individuals with type 2 diabetes and mild cognitive impairment. Diabetes Care 33, 1706-1711.

[42] Yu S, Fu AZ, Engel SS, Shankar RR, Radican L (2016) Association between hypoglycemia risk and hemoglobin A1C in patients with type 2 diabetes mellitus. Curr Med Res Opin 32, 1409-1416.

[43] Isik AT, Soysal P, Yay A, Usarel C (2017) The effects of sitagliptin, a DPP-4 inhibitor, on cognitive functions in elderly diabetic patients with or without Alzheimer's disease. Diabetes Res Clin Pract 123, 192-198.

[44] Khattar D, Khaliq F, Vaney N, Madhu SV (2016) Is metformin-induced vitamin B12 deficiency responsible for cognitive decline in type 2 diabetes? Indian J Psychol Med 38, 285-290.

[45] Heneka MT, Fink A, Doblhammer G (2015) Effect of pioglitazone medication on the incidence of dementia. Ann Neurol 78, 284-294.

[46] Herath PM, Cherbuin N, Eramudugolla R, Anstey KJ (2016) The effect of diabetes medication on cognitive function: 
Evidence from the PATH through life study. Biomed Res Int 2016, 7208429.

[47] Huang CC, Chung CM, Leu HB, Lin LY, Chiu CC, Hsu CY, Chiang $\mathrm{CH}$, Huang PH, Chen TJ, Lin SJ, Chen JW, Chan WL (2014) Diabetes mellitus and the risk of Alzheimer's disease: A nationwide population-based study. PLoS One 9, e87095.

[48] Ng TP, Feng L, Yap KB, Lee TS, Tan CH, Winblad B (2014) Long-term metformin usage and cognitive function among older adults with diabetes. J Alzheimers Dis 41, 61-68.

[49] Huang YC, Hsu CC, Lin WC, Yin TK, Huang CW, Wang PW, Chang HH, Chiu NT (2014) Effects of metformin on the cerebral metabolic changes in type 2 diabetic patients. Scientific WorldJournal 2014, 694326.

[50] Liccini A, Malmstrom TK, Morley JE (2016) Metformin use and cognitive dysfunction among patients with diabetes mellitus. J Am Med Dir Assoc 17, 1063-1065.

[51] Guo M, Mi J, Jiang QM, Xu JM, Tang YY, Tian G, Wang B (2014) Metformin may produce antidepressant effects through improvement of cognitive function among depressed patients with diabetes mellitus. Clin Exp Pharmacol Physiol 41, 650-656.

[52] Luchsinger JA, Perez T, Chang H, Mehta P, Steffener J, Pradabhan G, Ichise M, Manly J, Devanand DP, Bagiella E (2016) Metformin in amnestic mild cognitive impairment: Results of a pilot randomized placebo controlled clinical trial. J Alzheimers Dis 51, 501-514.
[53] Malmstrom TK, Voss VB, Cruz-Oliver DM, CummingsVaughn LA, Tumosa N, Grossberg GT, Morley JE (2015) The rapid cognitive screen (RCS): A point-of-care screening for dementia and mild cognitive impairment. J Nutr Health Aging 19, 741-744.

[54] McLean E, de Benoist B, Allen LH (2008) Review of the magnitude of folate and vitamin B12 deficiencies worldwide. Food Nutr Bull 29, S38-51.

[55] Ng TP, Aung KC, Feng L, Scherer SC, Yap KB (2012) Homocysteine, folate, vitamin B-12, and physical function in older adults: Cross-sectional findings from the Singapore Longitudinal Ageing Study. Am J Clin Nutr 96, $1362-1368$

[56] Kuan YC, Huang KW, Lin CL, Hu CJ, Kao CH (2017) Effects of metformin exposure on neurodegenerative diseases in elderly patients with type 2 diabetes mellitus. Prog Neuropsychopharmacol Biol Psychiatry 79, 77-83.

[57] Lin HC, Stein JD, Nan B, Childers D, Newman-Casey PA, Thompson DA, Richards JE (2015) Association of geroprotective effects of metformin and risk of open-angle glaucoma in persons with diabetes mellitus. JAMA Ophthalmol 133, 915-923.

[58] Kim B, Feldman EL (2015) Insulin resistance as a key link for the increased risk of cognitive impairment in the metabolic syndrome. Exp Mol Med 47, e149.

[59] Ye F, Luo YJ, Xiao J, Yu NW, Yi G (2016) Impact of insulin sensitizers on the incidence of dementia: A meta-analysis. Dement Geriatr Cogn Disord 41, 251-260. 